\title{
ELECTRICAL VOLTAGE GENERATION BY UTILIZING VIBRATION OF STRUCTURAL ELEMENTS
}

\author{
Biswarup Patra \\ Mechanical Engineering \\ Narula Institute of Technology \\ Kolkata 700109
}

\author{
Goutam Roy \\ Mechanical Engineering \\ Narula Institute of Technology \\ Kolkata 700109
}

\author{
Pijush Roy \\ Mechanical Engineering \\ Narula Institute of Technology \\ Kolkata 700109
}

\author{
K.Agarwal \\ Mechanical Engineering \\ Narula Institute of Technology \\ Kolkata 700109
}

\author{
R.Yadav \\ Mechanical Engineering \\ Narula Institute of Technology \\ Kolkata 700109
}

Abstract - Abstract: The firm raise in energy uses tied with pollution has encouraged the researchers to be focused on alternative ways to get pollution free non conventional energy sources. The world is slowly but surely moving towards a rigorous energy crisis, due to an increasing order of energy crossing its supply. Numerous researches are going on to develop different material, different ways and also different renewable fuels which can produce energy. In recent development, by collecting the energy from the environment with the help of wind, sun, water etc. are normally used to give power directly to electric devices or are stored in batteries. This is termed as energy harvestation. In recent studies a new way to harvest energy is seen by using piezoelectric material, generally deals with the energy produced due to mechanical vibration. When a piezoelectric element is strained, it charges up electrically. It is clearly observed that structural elements produce vibration when it comes under dynamic load. Usually different bridge structures come under dynamic load, as an example when a loaded vehicle passes through a bridge. A bridge structure can be compared with a beam under different boundary conditions. So if a precise study is done on energy harvestation by using piezoelectric patch from a beam under dynamic load then it can show a direction to utilize the vibration of different structures to generate electrical voltage. Some researchers have used the piezoelectric patch as long as the beam length to harvest energy. Since Piezoelectric material is very costly so it is not possible to use it to cover up the whole length of a bridge. In this study it is focused to find out a optimized way by which the vibration of different structures can be utilized to generate electricity. A mathematical as well as a finite element model is developed to obtain the voltage output from piezoelectric patch for different conditions.
Keywords - ABAQUS, Piezoelectric, Dynamic, Mode shape

\section{INTRODUCTION:}

In recent development, by collecting the energy from the environment with the help of wind, sun, water etc. are normally used to give power directly to electric devices or are stored in batteries. This is termed as energy harvestation. In recent studies a new way to harvest energy is seen by using piezoelectric material, generally deals with the energy produced due to mechanical vibration. These piezoelectric materials are commonly known as piezoelectric harvesters. The energy stored in the harvester is used to supply power to different electronic devices such as mobile phones, laptops and other portable devices. When a piezoelectric element is strained, it charges up electrically, and its charge is determined by its characteristics, amount of force, coupling of the material structure and performance. These piezoelectric harvesting material contains free dipoles, which can be changed or tampered through vibrations. Majority of the researches upto this point had generally laid its views on the characteristics of the energy harvesting medium instead of focusing on developing self powered device. [1] Zubair Butt et. al, 2016 in his work, developed a simple $1 \mathrm{DOF}$ analytical model to determine the voltage output from a Piezoelectric material at various frequency and loading condition. Simultaneously he had done an experimental as well as simulation work to compare the results.[2] ChangkiMo et. al,2010 in his research work he had developed a theoretical model of a unimorph piezoelectric harvester, in which he considered the radius of layer not as that of the substrate.[3] Dhingra Parul et. al. (2012) had shown in his study that energy harvestation by PZT is a new away for greener technologies which aims for a pollution free environment.[4] Ch Naveen Kumar (2015) had shown that the power harvesting method is a second-hand to carry out the use of PZT materials to convert the wasting 


\section{International Journal of Engineering Applied Sciences and Technology, 2020 \\ Vol. 4, Issue 10, ISSN No. 2455-2143, Pages 150-154 \\ Published Online February 2020 in IJEAST (http://www.ijeast.com)}

vibration energy into electrical energy and the generated voltage can be used to run different devices or can be stored. [5] Kumar Govind et. al. (2012) had shown in his paper, a method to produce environment friendly electricity using PZT by decreasing global warming.[6] B Panigrahi et. al. had shown a novel technique on harmonic stability following an iterative technique, which is used for dynamic analysis. [7] Banerjee Amit et. al. (2015), in their study developed a technique to analyze the dynamic response of a beam based on Timoshenko beam theory following Ritz method.[8] Panigrahi Brajesh(2015); In his study described a technique following the neutral surface approach , which is employed on clamped-clamped.[9] Liu Tiejun et. al. (2016); the research work shows the behavior of the effect of varying load on the health of structures using tied piezoelectric transducers.[10] Nan $\mathrm{Wu}$ et. al. (2011) in their work shows a way to get feedback from a cantilever beam with notch which is under dynamic load by using piezoelectric patches. [11] Wen Hui Duan et. al. (2010); described in their study that piezo electric material for the specific properties, can be used in many applications for structural health monitoring and repair. It is established from different studies that piezoelectric materials have notable sensing and exciting capacities.[12] Changki Mo et. al. (2010), This research study shows a theoretical model to predict the energy generation capability of a harvesting device based on piezoelectric membrane under varying pressure.

\section{MATHEMATICAL FORMULATION OF ANALYTICAL STUDY:}

Here at first the natural frequency and mode shape of beams under different condition is obtained by Rayleigh -Ritz method. In this study the Euler Bernoulli beam theory is considered to formulate the analytical equations.

Maximum $\mathrm{PE}$ and $\mathrm{KE}$ of a vibrating beam under free vibration can be expressed as in equation (1) and (2)

$$
\begin{gathered}
P E_{\max }=\frac{1}{2} E I \int_{0}^{l}\left[\frac{d^{2} U}{d x^{2}}\right]^{2} d x(1) \\
K E_{\max }=\left(\omega^{2}\right) \frac{1}{2} \rho A \int_{0}^{l} U^{2} d x
\end{gathered}
$$

Where $U=\sum_{0}^{N} a_{i} x^{i}$

$$
U=\sum_{0}^{N} a_{i} x^{i}
$$

The equation of motion of beam under external excitation force is given in equation (3)

$$
E I \frac{\partial^{4} U(x, t)}{\partial x^{4}}+\rho A \frac{\partial^{2} U(x, t)}{\partial t^{2}}=F(x, t)
$$

By applying separation of variables $1^{\text {st }}$ mode can be assumed as

$$
U(x, t)=U(x) S(t)
$$

The equation of motion for damped free vibration can be written in following way...

$$
\frac{d^{4} U(x)}{d x^{4}}-\frac{\rho A \omega^{2} U(x)}{E I}=0
$$

By using equation (4) into equation (3) and dividing by $\rho \mathrm{A}$

$$
\frac{E I Q(t)}{\rho A} \frac{\partial^{4} W(x)}{\partial x^{4}}+w(x) \frac{\partial^{2} Q(t)}{\partial t^{2}}=\frac{f(x, t)}{\rho A}
$$

Equation (7) comes by putting equation (4) into equation (6).

$$
\omega^{2} W(x) Q(t)+w(x) \frac{\partial^{2} Q(t)}{\partial t^{2}}=\frac{f(x, t)}{\rho A}
$$

Applying orthogonality property of mode shapes and integration along the entire length of beam, equation (7) comes as

$$
\frac{d^{2} S(t)}{d t^{2}}+\omega^{2} S(t)=\frac{1}{\rho A b} Q(t)
$$

Where $\mathrm{Q}(\mathrm{t})=\int_{0}^{l} F(x, t) U(x) d x$

$$
\mathrm{S}(\mathrm{t})=\mathrm{C} \cos \omega t+\mathrm{D} \sin \omega t+\frac{1}{\rho A q w} \int_{0}^{t} Q(\tau) \sin \omega(t-\tau) d \tau
$$

Where $\mathrm{U}(\mathrm{x})$ is the 1 st mode shape of vibrating beam.

\section{Piezoelectric patch}

PZT patch can be formulated as given by [29] Shengjie Zhao et. al.

$$
V=\frac{-e_{31} b(h+d)}{2 C_{v}} \int_{l_{1}}^{l_{2}} \frac{d^{2} U(x)}{d x^{2}} d x
$$




\section{International Journal of Engineering Applied Sciences and Technology, 2020 \\ Vol. 4, Issue 10, ISSN No. 2455-2143, Pages 150-154 \\ Published Online February 2020 in IJEAST (http://www.ijeast.com)}

Where, $\mathrm{V}$ is the voltage output from patch.

Where, $\mathbf{e}_{31}$ is the stress constant of piezoelectric material.

Finite Element Model

Linear dynamic study of Steady-state vibration obtains the behavior of an element, while vibrating at a fixed frequency. At first ABAQUS/Standard extracts the natural frequency of the element then it uses the extracted natural frequency to simulate the steady state response. In ABAQUS, the equation for steady state vibration of an element at $\alpha$ th mode is as given below.

$$
\ddot{q}_{\alpha}+c_{\alpha} \dot{q}_{\alpha}+\omega^{2} \mathrm{q}_{\alpha}=\frac{1}{m}\left(f_{1 \alpha}+\text { if } f_{2 \alpha}\right) \exp (\mathrm{i} \Omega \mathrm{t})
$$

The solution of the above equation can be expressed as

$$
q_{\alpha}=\mathrm{H}_{0 \alpha} f_{0 \alpha} \exp \mathrm{i}\left(\Omega \mathrm{t}+\varphi_{\alpha}\right)
$$

\begin{tabular}{|c|c|c|}
\hline Material properties & Aluminum & $\begin{array}{c}\text { Piezoelectric material, } \\
\text { Sparkler 2019 }\end{array}$ \\
\hline Material & Aluminum & PZT 5H \\
\hline Width & $50 \mathrm{~mm}$ & $50 \mathrm{~mm}$ \\
\hline Depth & $10 \mathrm{~mm}$ & $0.5 \mathrm{~mm}$ \\
\hline Length & $600 \mathrm{~mm}$ & $50 \mathrm{~mm}$ \\
\hline $\mathrm{E}_{11}$ & $69 \mathrm{GPa}$ & $113 \mathrm{GPa}$ \\
\hline $\mathrm{E}_{33}$ & $\mathrm{NA}$ & $105 \mathrm{GPa}$ \\
\hline $\mathrm{Y}$ & 0.29 & 0.31 \\
\hline $\mathrm{G}$ & & $-274 \times 10^{-12} \mathrm{~m} \mathrm{~V}^{-1}$ \\
\hline $\mathrm{d}_{31}$ & & $593 \times 10^{-12} \mathrm{~m} \mathrm{~V}^{-1}$ \\
\hline $\mathrm{d}_{33}$ & & $714 \times 10^{-12} \mathrm{~m} \mathrm{~V}^{-1}$ \\
\hline $\mathrm{d}_{15}$ & & 3100 \\
\hline Relative Dielectric Constant & & \\
\hline
\end{tabular}

Table: 1 Properties of Aluminum beam and PZT patch.

\section{RESULT AND DISCUSSION}

The analytically derived relations are at first coded in MATHAMATICA and then results are obtained for different conditions. Subsequently a Finite Element model is prepared by using ABAQUS 6.12. The finite element models of beam with tied piezoelectric patch is shown in Fig:1-2. Also a mesh convergence study is done which is shown in Fig: 3. A comparison between analytical and finite element analysis result is given in Table: 2 to show the accuracy of this research work.

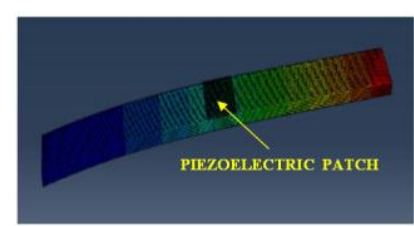

Fig:1

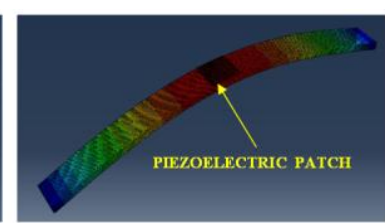

Fig:2
Fig: 3 clearly depicts that the Finite Element Model converges at 0.002 Global element size. So in this study the meshing is done considering 0.002 Global sizes and the type is taken 8 Node brick element.

\begin{tabular}{|c|c|c|c|c|c|}
\hline Beam Type & $\begin{array}{l}\text { Positionof } \\
\text { Patch(mm) }\end{array}$ & $\begin{array}{l}\text { Position } \\
\text { Load(mm) }\end{array}$ & \begin{tabular}{l|} 
Exciting \\
Frequency $(\mathrm{Hz})$
\end{tabular} & $\begin{array}{l}\text { Abaqus } \\
6.12(\mathrm{~V})\end{array}$ & Analytical(V) \\
\hline \multirow{5}{*}{ Cantilever } & 25 & 60 & 23 & 97 & 96.6862 \\
\hline & 75 & 120 & 23 & 324 & 323.424 \\
\hline & 300 & 300 & 23 & 706 & 705.692 \\
\hline & 525 & 540 & 21 & -148 & -147.656 \\
\hline & 575 & 600 & 21 & -26 & -25.337 \\
\hline & & & & & \\
\hline \multirow{4}{*}{$\begin{array}{l}\text { Simply } \\
\text { Supported }\end{array}$} & 25 & 60 & 63 & -125 & -124.272 \\
\hline & 75 & 120 & 63 & -694 & -693.027 \\
\hline & 300 & 300 & 63 & -3082 & -3081 \\
\hline & 525 & $\begin{array}{l}500 \\
480\end{array}$ & 61 & 705 & 704.296 \\
\hline
\end{tabular}

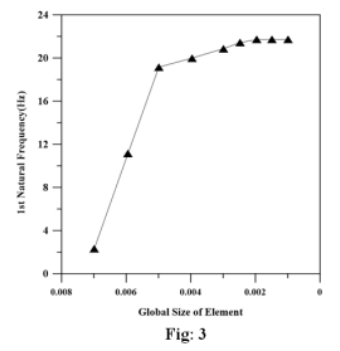

Table: 2 Comparison of analytical results with the ABAQUS simulations results.

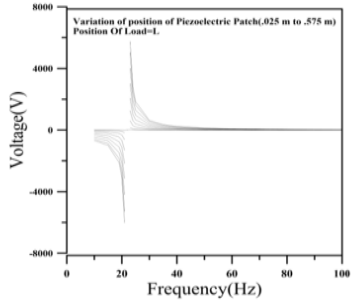

Fig:4

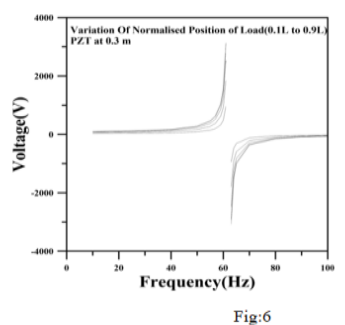

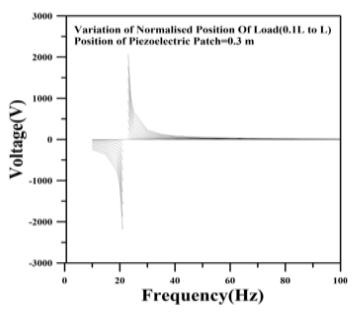

Fig:

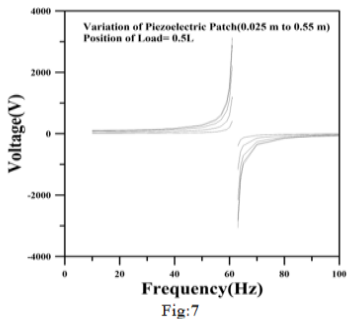




\section{International Journal of Engineering Applied Sciences and Technology, 2020 \\ Vol. 4, Issue 10, ISSN No. 2455-2143, Pages 150-154 \\ Published Online February 2020 in IJEAST (http://www.ijeast.com)}

Fig:4-7 depicts the characteristic of voltage output from the Piezo electric patch for different conditions. Fig: 4 and 7 shows the variation in voltage output for different patch locations same way Fig:5 and 6 shows the output variation for different position of exciting force. Here Fig: 4-5 are of cantilever beam and Fig:6-7 are for simply supported beam.
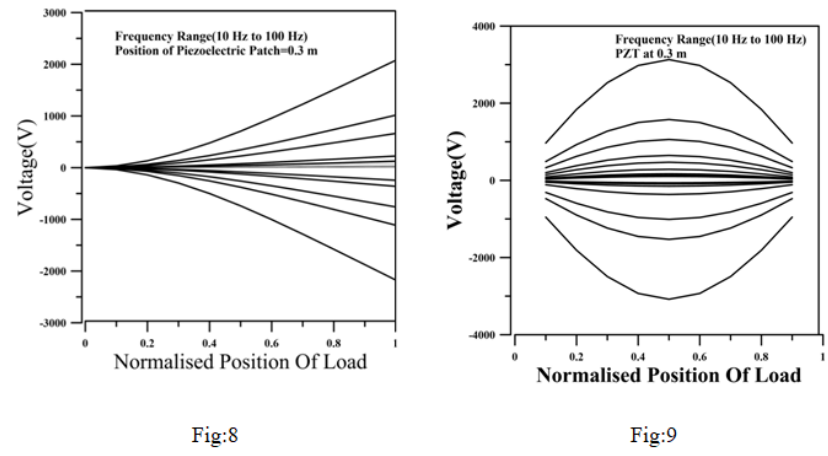

Fig:8 and 9 describes the voltage output variation for a fixed patch position, with varying position of load. Here Fig:8,9 are respectively for Cantilever and simply supported beams. It is very clear from above two figures that when the load is at open end for cantilever and at the mid for simply supported the Patch generates maximum voltage for all frequencies. This is quite natural.

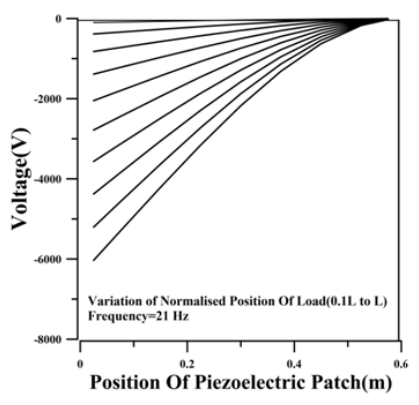

Fig:10

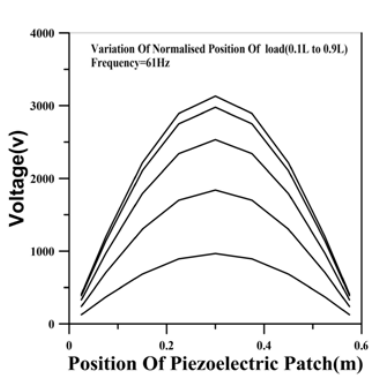

Fig:11
Fig: 10 and 11 respectively shows the output voltage variation of patch for cantilever and simply supported. In both cases, the study is done for varying position of patch and Location of load, while vibrating at a frequency below than 1 st natural frequency i.e $22 \mathrm{~Hz}, 62 \mathrm{~Hz}$ respectively for Cantilever and Simply supported beam. The study very clearly depicts that when the patch is at fixed end of cantilever beam and at mid of simply supported beam it generates maximum voltage.
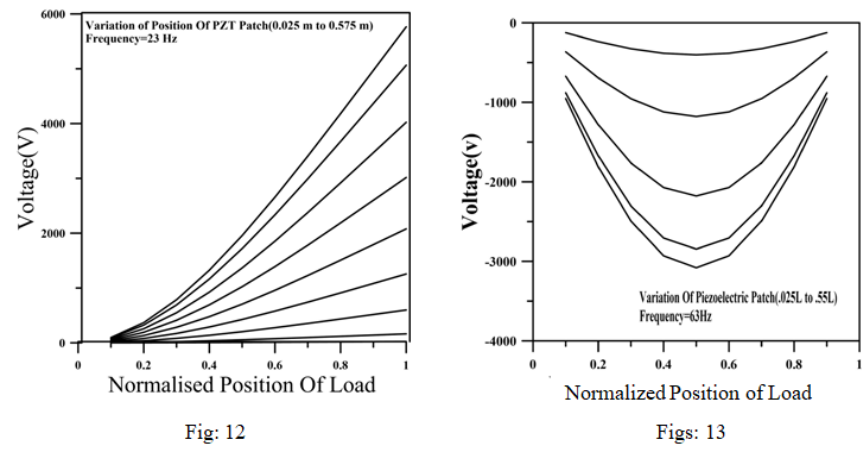

Fig: 12 and 13 shows the variation of output voltage for different load positions while vibrating at a frequency just above to their respective 1st natural frequency. Here Fig: 12, 13 are for cantilever and simply supported beams respectively. The study clearly depicts that when the load is at open end for cantilever and at mid for simply supported beam, the patch generates maximum voltage.

Conclusion: A Numerical (FEM) as well as analytical study is done to show the variation of voltage output from piezo electric patch which is tied on different types of beam. It is shown that vibration of structural elements can be utilized for energy harvestation. An analytical model is developed to get the voltage output through piezo electric patch which is tied on a vibrating element. To show the accuracy of this analytical model, subsequently a FEM model is prepared by using ABAQUS 6.12. It is observed, the result are approximately same. It is easily concluded through this study for a cantilever beam, that when the patch is at fixed end, load is at open end and if the element vibrates near its natural frequency then the patch generates maximum voltage output. Same way it also can be concluded for simply supported beam that when patch is at beam and load is also at mid, the energy output is maximum. It is seen that in the real world most of the bridges are in types of beam, so it can be concluded that the vibration of this kind of structures can be utilized to generate electrical voltage. Indeed this study will help the researchers who are interested to develop new ways to generate electrical voltage.

\section{REFERENCES}

[1] Butt Zubair et. al,(2016);Generation of electrical energy using lead zirconate titanate (PZT-5A) piezoelectric material: Analytical, numerical and experimental verifications; Journal of Mechanical Science and Technology 30 (8) (2016) 1 6; DOI 10.1007/s12206-016-0913-y

[2] ChangkiMo et. al,(2010); Analysis of piezoelectric circular 
diaphragm energy harvesters for use in a pressure fluctuating system; Smart Mater. Struct. 19 (2010) 025016 (10pp); doi:10.1088/0964-1726/19/2/025016

[3] Dhingra Parul et. al(2012); Energy Harvesting using Piezoelectric Materials; Special Issue of International Journal of Computer Applications (0975 - 8887)

[4] Ch Naveen Kumar(2015); Journal of Physics: Conference Series662(2015)012031;doi:10.1088/1742-6596/662/1/012031

[5] Kumar Govind et. al. (2012); Ecosecurity energy harvesting using piezoelectric crystal; https://ieeexplore.ieee.org/xpl/conhome/6192355/proceeding https://doi.org/10.1109/SCES.2012.6199116

[6] B Panigrahi et. al.(2017); Study of non-linear dynamic behavior of open cracked functionally graded Timoshenko beam under forced excitation using harmonic balance method in conjunction with an iterative technique; Applied Mathematical Modeling 57 (2018) pp 248-267

[7] Banerjee Amit et. al. (2015); Crack modelling and detection in Timoshenko FGM beam under transverse vibration using frequency contour and response surface model with GA; DOI: 10.1080/10589759.2015.1071812;

[8] Panigrahi Brajesh et. al. (2015); Nonlinear modelling and dynamic analysis of cracked Timoshenko functionally

graded beams based on neutral surface approach; DOI: $10.1177 / 0954406215576560$

[9] Liu Tiejun et. al. (2016); Influence of axial loads on the health monitoring of concrete structures using embedded piezoelectrictransducer;DOI:10.1177/1475921716670573

[10] Nan Wu et. al. (2011); An experimental study on the repair of a notched beam subjected to dynamic loading with piezoelectric patches; doi:10.1088/0964-1726/20/11/115023;

[11] Wen Hui Duan et. al. (2010); Applications of Piezoelectric Materials in Structural Health Monitoring and Repair: Selected Research Examples; Materials 2010, 3, 51695194; doi:10.3390/ma3125169

[12] Changki Mo et. al. (2014); This paper presents a comprehensive theoretical model for predicting the energy generating performance of an energy harvesting device that uses a piezoelectric circular membrane subject to pressure fluctuation; doi:10.1088/0964-1726/23/4/045005 